Brit. J. industr. Med., 1955, 12, 304.

\title{
THE FORMATION OF PHOSGENE BY THE ACTION OF HOT SURFACES AND ITS ABSENCE WHEN TOBACCO IS SMOKED IN ATMOSPHERES CONTAINING CHLORINATED HYDROCARBON VAPOURS
}

\author{
BY \\ J. LITTLE \\ From Imperial Chemical Industries Ltd., General Chemicals Division, Widnes, Lancs
}

(RECEIVED FOR PUBLICATION APRIL 22, 1955)

When trichloroethylene or certain other solvent vapours are heated to a temperature of $400^{\circ} \mathrm{C}$. or more, or when the liquids decompose by exposure to light on standing in air, phosgene is produced. It is generally believed or assumed from this that when cigarettes are smoked in atmospheres contaminated with the solvent vapours phosgene is also produced and inhaled. However, nowhere in the literature is experimental evidence given of phosgene being positively identified in the inhaled gases from a cigarette smoked in these contaminated atmospheres although the danger has been pointed out by several writers, including McNally (1937), Oettingen (1937), and Converse (1938). A secondary danger may exist from the glowing cigarette tip in the atmosphere around the cigarette.

Elkins and Levine (1939) carried out a comprehensive series of tests in which the effluent from cigarettes smoked in atmospheres containing a number of halogen-containing hydrocarbon vapours was examined. They did not test the inhaled gases specifically for phosgene, but, on the basis of the halide content of the exit gases, calculated that even if all the halogen found was so present it would not constitute a health hazard.

The tolerance limit for continual exposure to phosgene in the atmosphere is stated by Patty (1949) to be 1.0 part per million by volume, a concentration of 2 parts per million being dangerous for prolonged exposure.

In view of the extremely toxic nature of phosgene, therefore, it is essential that smoking in the presence of these solvents be forbidden unless it can be demonstrated by a test of adequate sensitivity that phosgene is not present in the exhaled tobacco smoke or formed in the surrounding atmosphere.
The Detection of Phosgene

Phosgene in the atmosphere may be detected by means of a coloration produced when the atmosphere is brought into contact with the mixed reagent, $p$-dimethylaminobenzaldehyde and diphenylamine. The standard method used for testing described by the Department of Scientific and Industrial Research (1939) uses a paper disc impregnated with this reagent. The atmosphere is drawn through the paper at a prescribed rate by means of a hand pump until a standard coloration is produced. The volume of atmosphere drawn through is a measure of the phosgene content, which is read from a table. This test was used to obtain the results given in Table 2 . The test is sensitive down to about 0.5 parts per million, which is about the tolerance limit for phosgene.

It has been found that when the reagent is deposited on glass ground to coarse powder and the test applied by drawing the atmosphere through a narrow glass tute containing the glass powder impregnated with the reagent, then the sensitivity is increased at least tenfold and a concentration of phosgene of 0.05 parts per million by volume may be detected. Glass powder which passes between sieves 25-36 B.S. mesh was found to be most suitable ; a narrow tube, internal diameter $6 \mathrm{~mm}$., was used, the reagent column length being about $10 \mathrm{~cm}$. The test may be made approximately quantitative by comparison with coloured glass in a tube. A suitable reference colour is obtained by washing glass powder in a solution of $10 \mathrm{mg}$. of "waxoline yellow" in $100 \mathrm{ml}$. alcohol, then drying off the alcohol in a downward stream of nitrogen. The results given below are referred to this colour standard. 
The colour produced by phosgene is proportional to the volume of the atmosphere drawn through the tube, but is also dependent on the rate at which the atmosphere is drawn through. Table 1 gives results obtained by drawing the atmosphere through the tube at a gas rate of 30 litres per hour, which is the rate used in the subsequent smoking experiments.

TABLE 1

DETERMINATION OF PHOSGENE IN ATMOSPHERE BY COMPARING COLOUR PRODUCED IN AN INDICATOR TUBE WITH AN ARBITRARY COLOUR STANDARD

\begin{tabular}{c|c|c}
\hline $\begin{array}{c}\text { Concentration of } \\
\text { Phosgene in the } \\
\text { Atmosphere } \\
\text { (p.p.m.) }\end{array}$ & $\begin{array}{c}\text { Volume of Gas drawn } \\
\text { to Match the } \\
\text { Standard Colour } \\
\text { (litres) }\end{array}$ & $\begin{array}{c}\text { Time Taken to Match } \\
\text { the Standard Colour } \\
\text { (minutes) }\end{array}$ \\
\hline 0.05 & 6 & 12 \\
0.20 & $1 \frac{1}{2}$ & $2 \frac{1}{2}$ \\
0.50 & 1.0 & $1 \frac{1}{2}$ \\
\hline
\end{tabular}

The standard colour at this flow rate is equivalent to about $1 \mu \mathrm{g}$. of phosgene.

\section{Formation of Phosgene by Pyrolysis}

When atmospheres containing the vapours of chlorine-containing hydrocarbons are exposed to hot surfaces at temperatures greater than $400^{\circ} \mathrm{C}$., decomposition takes place with the formation of phosgene. The results quoted in Table 2 were obtained by drawing air containing the solvent vapour through a silica tube. The silica tube was packed with silica lumps and heated to the stated temperature over a length of 6 in. All the results were obtained from the same experimental conditions and hence it is possible to obtain from them a rough idea of the relative stability of the vapours.

TABLE 2

COMPARISON OF AMOUNTS OF PHOSGENE FORMED WHEN ATMOSPHERES CONTAINING VARIOUS CHLORINATED HYDROCARBON VAPOURS ARE PASSED THROUGH A HEATED SILICA TUBE UNDER CERTAIN STANDARDIZED CONDITIONS

\begin{tabular}{|c|c|c|c|c|c|c|}
\hline & \multirow{2}{*}{$\begin{array}{l}\text { Vapour } \\
\text { Concen- } \\
\text { tration } \\
(\% \mathrm{v} / \mathrm{v})\end{array}$} & \multicolumn{5}{|c|}{$\begin{array}{l}\text { Phosgene Produced at Stated } \\
\text { Temperature (parts per million) }\end{array}$} \\
\hline & & $400^{\circ} \mathrm{C}$ & $500^{\circ} \mathrm{C}$ & $600^{\circ} \mathrm{C}$ & $700^{\circ} \mathrm{C}$ & $800^{\circ} \mathrm{C}$ \\
\hline $\begin{array}{l}\text { Methylene chloride.. } \\
\text { Chloroform .. } \\
\text { Carbon tetrachloride }\end{array}$ & $\begin{array}{l}0.5 \\
0.4 \\
0.4\end{array}$ & $\begin{array}{l}\text { N.D. } \\
<1 \\
\text { N.D. }\end{array}$ & $\begin{array}{l}<1 \\
15 \\
7\end{array}$ & $\begin{array}{r}<1 \\
130 \\
25\end{array}$ & $\frac{3}{-}$ & $\frac{20}{-}$ \\
\hline $\begin{array}{l}\text { Dichloroethylene } \\
\text { Diche }\end{array}$ & 0.4 & & & & & \\
\hline $\begin{array}{l}\text { (sym. cis.) } \\
\text { Dichloroethylene }\end{array}$ & 0.5 & N.D. & 4 & 50 & - & - \\
\hline $\begin{array}{l}\text { (sym. trans.) } \\
\text { Trichloroethylene }\end{array}$ & $\begin{array}{l}0.6 \\
0.3\end{array}$ & N.D. & N.D. & 30 & 20 & - \\
\hline $\begin{array}{l}\text { Perchloroethylene } \cdots \\
\text { Ethylene dichloride }\end{array}$ & U.3 & N.D. & N.D. & 1 & $\overline{10}$ & 二 \\
\hline $\begin{array}{l}\text { (sym.) } \\
\text { Tetrachloroethane }\end{array}$ & $0 \cdot 12$ & N.D. & N.D. & 3 & 5 & 15 \\
\hline $\begin{array}{lll}(\text { sym.) } & \ldots\end{array}$ & $0 \cdot 3$ & N.D. & 1 & 7 & - & - \\
\hline
\end{tabular}

N.D. = not detected. The limit of detection in this case was 0.5 p.p.m.
Application of the Test for Phosgene to the Exhaled Gas from Cigarettes Smoked in the Contaminated Atmosphere

The physical characteristics of normal smoking have been discussed by Bradford, Harlan, and Hanmer (1936). and by Pfyl (1933). For the experiments described in this paper a continuous smoking rate of $\mathbf{3 0}$ litres per hour was decided upon. This is less than the peak rate in normal puffing, but considerably greater than the average rate of inhalation.

In order to apply the test for phosgene to the exhaled gases from the cigarettes it is first necessary to remove the smoke component, which is in fact a tarry mist consisting of a variety of organic substances. This is most easily accomplished by means of a jet scrubber, in which the smoke impinges against a glass surface through a narrow annular space.

The cigarette was fitted into a glass holder inside a wide glass tube, through which the prepared atmosphere was passed, the cigarette tip being lightly smeared with silicone grease to make the joint air-tight. The atmosphere was drawn through by means of a water pump, the rate of flow, controlled by an air leak, being indicated by a flow meter. The apparatus consisted of the smoking chamber, the jet scrubber to remove the tar, the indicator tube and the water pump and flow meter. The pressure drop through the apparatus, which progressively increased during smoking, was measured by means of a simple manometer, and a predetermined correction was applied to the flow rate indicated to maintain the required flow rate calculated to atmospheric pressure.

Atmospheres containing the solvent were prepared by passing a measured stream of air through a sintered glass bubbler containing the liquid into a second stream of uncontaminated air, the concentration of vapour obtained under the set condition (temperature, flow rates, etc.) being calculated from the vapour pressures of the solvents. Atmospheres containing phosgene were prepared from a cylinder containing pure phosgene, the phosgene being bled into a measured flow of air through a calibrated bubbler containing concentrated sulphuric acid. Atmospheres containing down to 10 parts per million by volume of phosgene were prepared by a single dilution; atmospheres containing down to 0.05 parts per million were obtained by a second dilution.

Smoking experiments were made in atmospheres containing trace concentrations of solvent vapours. In no case was phosgene detected, the limit of detection being 0.05 parts per million by volume. 
However, it was found that even when cigarettes were smoked in atmospheres which contained phosgene, phosgene was not detected in the effluent. Neither was phosgene detected when, after smoking, the stub was removed from the holder and the phosgene-containing atmosphere continued to be drawn through the empty holder. It was subsequently found that in this apparatus containing the tar from a single cigarette, an atmosphere containing 50 parts per million by volume of phosgene could be drawn through for about 20 minutes at the experimental smoking rate of 30 litres per hour before even a trace of phosgene was detected. The smaller amounts of phosgene combined effectively with the tar. This absorption of phosgene by the tar is not a simple physical solution since the phosgene absorbed cannot subsequently be displaced into a stream of air, and is probably chemically combined with the tar to form a new compound.

The conclusion to be drawn from these experiments is that phosgene, if formed, is unlikely to survive through a lighted cigarette. There remains, however, the possibility that the phosgene may not be entirely absorbed within the cigarette. In order to relate the experimental results to normal smoking in which the emergent gases from the cigarette pass immediately into the mouth, the test must either be applied at the point of emergence of the smoke from the cigarette, which is impracticable, or the capacity of the tar leaving the cigarette to absorb phosgene must be eliminated.

The absorption of phosgene by tobacco tar is probably due to basic organic substances in the tar. It was found that when the tar deposited in the apparatus was acidified by a stream of hydrogen chloride vapour it was no longer an avid absorbent of phosgene. Only a slight residual absorption remained; for example, the colour test obtained from 0.2 parts per million by volume of phosgene was obtained in about four minutes using the same flow conditions as were used to obtain the values given in Table 1. The hydrogen chloride, to which the indicator is also highly sensitive, was conveniently removed by including a tube containing pumice granules loaded with a mixture of sodium thiosulphate, sodium iodide, and potassium iodate before the indicator tube. A trace of hydrogen sulphide was evolved from the acid absorbent but this was removed by also including a tube containing lead acetate granules.

This procedure was applied to the smoking experiments. A stream of the hydrogen chloride was passed through a fine tube into the cigarette holder to mix with the smoke emerging from the cigarette.

In the experiments, usually five cigarettes were smoked in succession, at the prescribed flow rate.
Hydrogen chloride was introduced into the exit gas from the cigarettes at a sufficient rate to provide a slight excess of acid, which passed through into the pumice absorbent forming a brown stain at the beginning of the tube. The cigarettes were smoked completely through except in the experiments where phosgene was added to the smoked atmosphere, and in these instances the cigarettes were smoked down to a stub length of about half an inch.

In all the tests applied, only a trace colour was produced in the indicator tube during smoking. This trace colour, obtained equally from smoking in a pure atmosphere and in a contaminated atmosphere, indicated a phosgene level not greater than $0 \cdot 1$ parts per million. This " blank" colour was obtained even when a tube containing sodium hydroxide granules was included before the indicator tube and was therefore not due to phosgene. However, because of the formation of this trace "blank" colour the limit of detection of phosgene is raised to $0 \cdot 1$ parts per million. Results obtained are summarized in Table 3.

TABLE 3

DETECTION OF PHOSGENE IN INHALED GASES FROM CIGARETTES SMOKED IN ATMOSPHERES CONTAMINATED WITH CHLORINE-CONTAINING HYDROCARBON VAPOURS

\begin{tabular}{|c|c|c|c|}
\hline Solvent & & $\begin{array}{c}\text { Concentrations of } \\
\text { Solvent Vapour in } \\
\text { the Atmosphere } \\
\text { (p.p.m. v/v) }\end{array}$ & $\begin{array}{c}\text { Phosgene in the } \\
\text { Inhaled Gases } \\
\text { (p.p.m. v/v) }\end{array}$ \\
\hline $\begin{array}{l}\text { Trichloroethylene } \\
\text { Trichloroethylene } \\
\text { Tetrachloroethane } \\
\text { Chloroform . } \\
\text { Carbon tetrachloride } \\
\text { Perchloroethylene } \\
\text { Phosgene } \quad \text {. } \\
\text { Phosgene } \quad \text {. }\end{array}$ & $\begin{array}{l}\cdots \\
\cdots \\
\cdots \\
\cdots \\
\cdots \\
\cdots\end{array}$ & $\begin{array}{c}2000 \\
200 \\
10 \\
300 \\
50 \\
200 \\
20 \\
0 \cdot 2\end{array}$ & 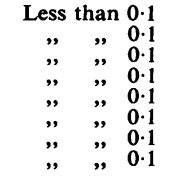 \\
\hline
\end{tabular}

Application of the Test for Phosgene to the Atmosphere Surrounding the Cigarette

The presence of a glowing cigarette tip in an atmosphere containing the solvent vapour might be expected to produce phosgene in the surrounding atmosphere, but the formation would depend upon the conditions around the tip, such as the presence of tobacco tar in the evolved smoke and the turbulence of the atmosphere. Phosgene, if formed, would be rapidly dissipated in the surrounding atmosphere and the principal hazard would be to the smoker. Another hazard would result from, possibly several, cigarette stubs smouldering in an ash tray.

During inhalation of air at the rate of 30 litres per hour, the cigarette glow is continuous and only a small amount of smoke rises from the tip. In normal smoking, where the inhalation is discontinuous, the smouldering cigarette evolves a greater 
amount of smoke. The temperature of the glowing tip during inhalation is about $950^{\circ} \mathrm{C}$. falling to about $700^{\circ} \mathrm{C}$. in the smouldering condition.

In normal smoking, contact between the atmosphere and the glowing cigarette tip is mainly due to simple convection and diffusion. Induced movement of the atmosphere around the tip would be more favourable for the formation of phosgene and a satisfactory condition to apply in the present experimental investigation. A sampling technique should not, however, create too great an air flow since this would have a cooling effect on the tip. The standard rate of 30 litres per hour was considered to be a satisfactory rate of sampling for the experiments.

In the experiments made to examine the surrounding atmosphere, the cigarette was fixed into a vertical holder inside a wide glass smoking chamber, through which the prepared atmosphere was passed. The cigarettes were smoked at the rate of 30 litres of air per hour and the test was made by drawing the atmosphere from around the cigarette tip through the indicating tube, also at the rate of 30 litres per hour, as stated above. The prepared atmosphere was passed through the smoking chamber at a rate of about 70 litres per hour. The test for phosgene was applied directly to the atmosphere in the vicinity of the smoked cigarette tip and, even in the smouldering condition, the indicating granules were only slightly discoloured brown by the smoke. The brown colour was distinctly different from the yellow colour due to phosgene.

A preliminary experiment was made by smoking in an atmosphere which contained 20 parts per million phosgene. When the atmosphere was drawn from near the glowing tip, but out of contact with the rising smoke, a coloration equivalent to the 20 parts per million was obtained, but when the atmosphere was drawn from above the glowing cigarette in the path of the evolved smoke a diminished coloration was obtained. In a second preliminary experiment when the prepared atmosphere contained one part per million phosgene, the phosgene could not be detected in the atmosphere in contact with the evolved smoke.

Experiments were made by smoking in atmospheres contaminated by the solvent vapours. In no case was phosgene detected. The results are given in Table 4. The atmosphere was drawn from two positions within the smoking chamber, from a position $\frac{1}{2}$ in. to the side of the glowing tip, and from a position about 2 in. above the tip, directly in the path of the rising smoke. Two cigarettes were smoked for each test, the time taken being four minutes. The standard colour under these condi- tions would represent about $0 \cdot 1$ parts per million phosgene. The limit of detection of the test applied, therefore, is better than $0 \cdot 1$ parts per million.

TABLE 4

DETECTION OF PHOSGENE IN THE ATMOSPHERE AROUND CIGARETTES SMOKED IN ATMOSPHERES CONTAMINATED WITH CHLORINE-CONTAINING HYDROCARBON VAPOURS

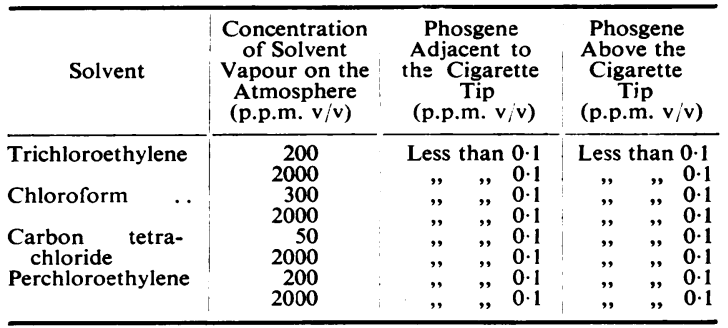

The results given are based on atmospheres drawn from around the tip at the rate of 30 litres per hour.

\section{Conclusion}

When atmospheres containing the vapour of certain chlorine-containing hydrocarbons are exposed to hot surfaces at temperatures greater than $400^{\circ} \mathrm{C}$. decomposition takes place with the formation of phosgene. The concentration of phosgene which may accumulate in the neighbourhood of hot surfaces will naturally depend on a variety of conditions, including the concentration of the solvent vapour in the atmosphere and the temperature of the hot surface.

Phosgene is not found in the vicinity of the glowing tip of a cigarette smoked in the contaminated atmospheres and even when a trace of phosgene is added to the atmosphere it rapidly decomposes in the presence of the evolved smoke. The limit of detection of phosgene in the atmosphere by the test applied is 0.1 parts per million by volume, but even if this concentration were present, it would be rapidly dissipated in the surrounding atmosphere.

When cigarettes are inhaled in atmospheres contaminated with these solvent vapours phosgene is not detected in the exit gas. Even if phosgene is formed or is present at the ignited tip it does not survive through the cigarette. The limit of detection of phosgene in the cigarette exit gases by the experimental technique applied is also $0 \cdot 1$ parts per million by volume. Assuming that a man smokes a cigarette in five minutes and that his normal rate of respiration is 10 litres per minute, then only one fiftieth of the atmosphere breathed consists of the exit gases from the cigarette, hence even though the concentration of phosgene determined is less than 0.1 parts per million the maximum possible con- 
centration of phosgene to which the man is exposed is 0.002 parts per million.

\section{Summary}

Comparative tests made by passing atmospheres containing certain chlorine-containing solvent vapours through a heated silica tube show that phosgene is formed when the surface temperature is greater than $400^{\circ} \mathrm{C}$.

A test for phosgene in an atmosphere has been developed which can be applied to measure a concentration of 0.05 parts per million by volume.

An experimental technique has been devised to apply this test to determine the phosgene in the exit gas from the cigarette which is inhaled and in the atmosphere surrounding the glowing tip, when cigarettes are smoked in these solvent-contaminated atmospheres. In no case was phosgene detected and even when phosgene was added to the atmosphere it was destroyed by passage through the cigarette being smoked.

Part of the work reported here, especially the work on the decomposition by hot surfaces, was carried out by A. G. Trenery and J. Watt.

\section{REFERENCES}

Bradford, J. A., Harlan, W. R., and Hanmer, H. R. (1936). Industr. Engn Chem., 28, 836.

Converse, J. D. (1938). Canad. Chem. Metall., 22, 361.

Department of Scientific and Industrial Research (1939). Methods for the Detection of Toxic Gases in Industry, Leaflet No. 8, Phosgene. H.M. Stationery Office, London.

Elkins, H. B., and Levine, L. (1939). J. industr. Hyg., 21, 221.

Elkins, H. B., and Levine, L. (1939). J. industr. Hyg.,
McNally, W. D. (1937). IIdustr. Med., 6, 539. $19,422$.

Oettingen, W. V. von (1937). J. industr. Hyg., 19, 422.

Patty, F. A. (1949). Industrial Hygiene and

Pfyl, B. (1933). Z. Untersuch. Lebensmitt., 66, 501. 